\title{
Panorama da sustentabilidade em um contexto urbano/ metropolitano na Amazônia a partir de duas ferramentas internacionais
}

Em uma metrópole os limites físicos entre os municípios que a compõem são praticamente indistinguíveis. As áreas metropolitanas se caracterizam por apresentar um fluxo intenso de pessoas, bens e serviços, e também, problemas e questões que ultrapassam a jurisdição municipal. Essas questões devem ser avaliadas e discutidas de maneira abrangente e inter-relacionada, principalmente em relação à perspectiva da gestão metropolitana e sustentabilidade. Neste contexto, o trabalho objetivou avaliar a sustentabilidade da região metropolitana de Belém sob a perspectiva de dois instrumentos bem conhecidos internacionalmente, o Barômetro da Sustentabilidade (BS) e o Painel da Sustentabilidade (PS). Com a aplicação dos dois instrumentos, buscou-se testar se essas ferramentas produzem resultados semelhantes e assim discutir sobre as principais limitações, vantagens e desvantagens que cada um apresenta em avaliar a sustentabilidade. Os resultados encontrados mostram que, em termos gerais, os instrumentos apresentam a mesma tendência, porém houve algumas distorções. Apesar disso, independentemente da escolha da ferramenta, ambas oferecem um diagnóstico amplo acerca dos temas e dimensões da sustentabilidade. Informações essas, que podem servir para basear a formulação de políticas e a definição de ações e prioridades.

Palavras-chave: Indicadores de Austentabilidade; Barômetro da Sustentabilidade; Painel da Sustentabilidade; Metrópole Amazônica.

\section{Overview of sustainability in an urban metropolitan context in the Amazon from the perspective of two international tool}

\begin{abstract}
In a metropolitan area the physical boundaries between the municipalities that compose it are practically indistinguishable. Metropolitan areas are characterized by an intense flow of people goods and services, as well as problems and issues that go beyond municipal jurisdiction. These issues should be evaluated and discussed in a comprehensive and interrelated way, especially in relation to the metropolitan management and sustainability perspective. In this context, the objective of this study was to evaluate the sustainability of Belém Metropolitan area, Pará state, Brazil, from the perspective of two internationally well-known systems, the Barometer of Sustainability (BS) and the Dashboard of Sustainability (PS). From the application of the two systems, we sought to test if these tools produce similar results and thus to discuss about their main limitations, advantages and disadvantages in assessing sustainability. The results show that, in general, the systems have the same tendency, but there were some distortions. Despite this, regardless of the tool chosen, both offer a broad diagnosis about the themes and dimensions of sustainability. These informations can serve as a basis for policy formulation and definition of actions and priorities.

Keywords: Indicators of Sustainability; Barometer of Sustainability; Dashboard of Sustainability; Amazonian Metropolis.
\end{abstract}

Topic: Engenharia Ambiental

Reviewed anonymously in the process of blind peer.

Fabiana da Silva Pereira (ib

Universidade Federal do Pará, Brasil

http://lattes.cnpq.br/2302988398943200

http://orcid.org/0000-0003-2881-6952

ambiental.fabiana@hotmail.com

Ima Célia Guimarães Vieira (it)

University Of Stirling, Escócia

http://lattes.cnpq.br/3761418169454490

http://orcid.org/0000-0003-1233-318X

ima@museu-goeldi.br

Peter Mann de Toledo (ic

University of Colorado, Estados Unidos

http://lattes.cnpq.br/3990234183124986

http://orcid.org/0000-0003-4265-2624

peter.toledo@hotmail.com
Received: 12/07/2017

Approved: 13/10/2017
Referencing this:

PEREIRA, F. S.; VIEIRA, I. C. G.; TOLEDO, P. M.. Panorama da sustentabilidade em um contexto urbano/ metropolitano na Amazônia a partir de duas ferramentas internacionais. Revista IberoAmericana de Ciências Ambientais, v.8, n.4, p.111-127, 2017. DOI: http://doi.org/10.6008/SPC2179-6858.2017.004.0010 


\section{INTRODUÇÃO}

O processo de urbanização no Brasil acelerou-se a partir da segunda metade do século XX, com profundas transformações estruturais tanto na sociedade quanto na economia do país (BRITO et al., 2001; BRITO et al., 2005). A velocidade com que esse processo se deu, levou o país a ter uma população urbana maior que a rural já na década de 60 (BRITO et al., 2005; BRITO, 2006). Concomitante a esse processo, ocorria também outro fenômeno no Brasil: a metropolização. Existem 37 regiões metropolitanas e 3 de regiões integradas de desenvolvimento (Rides) no país, onde residem cerca de $46 \%$ da população brasileira, sendo as maiores concentradas nas regiões Sul e Sudeste (IPEA, 2011). Na Amazônia brasileira, existem 3 regiões metropolitanas, sendo a região metropolitana de Manaus a maior, seguida pela região metropolitana de Belém.

A região metropolitana de Belém (RMB) é a segunda maior região metropolitana do Norte do país, concentrando aproximadamente um terço da população do estado do Pará, com um grau de urbanização de 96,1\% (IPEA, 2014). Assim como outras metrópoles no restante do país, o crescimento da RMB é recente e se deu de forma acelerada. A metrópole enfrenta diversos problemas de ordem ambiental, política e socioeconômica (PEREIRA et al., 2016), com grande desigualdade entre os municípios que a compõem. Como em uma região metropolitana os limites entre os municípios são praticamente indistinguíveis, com um fluxo intenso de pessoas, bens e serviços, há problemas e questões que ultrapassam os limites municipais. Por esta razão, devem ser avaliados e discutidos de maneira abrangente e interrelacionada, principalmente em relação à perspectiva da gestão metropolitana e sustentabilidade (FREITAS, 2009).

Uma maneira de fazer tal avaliação é através de índices de sustentabilidade, os quais dão uma resposta mais objetiva e completa acerca das dimensões que envolvem o desenvolvimento sustentável (VAN BELLEN, 2004; SICHE et al., 2007), produzindo informações que podem embasar tomadores de decisão de forma a priorizar, direcionar e potencializar ações e políticas públicas para a região.

Ainda há muitas incertezas sobre quais sistemas de indicadores ou índices são mais adequados para serem utilizados em determinadas escalas e contextos. Existem, na literatura, trabalhos que abordam e comparam diferentes índices e métodos de avaliação da sustentabilidade (VAN BELLEN, 2004; LIRA et al., 2008; GUIMARÃES et al., 2009; MORI et al., 2012; SINGH et al., 2012; MARCHAND et al., 2014). Entretanto, pouco se sabe a respeito dos resultados destes quando aplicados a um mesmo contexto e, principalmente, se esses resultados sofrem alguma distorção em razão do tipo de modelo de métrica da sustentabilidade adotado.

Nesse contexto, o trabalho objetivou avaliar a sustentabilidade da região metropolitana de Belém sob a perspectiva de dois instrumentos bem conhecidos internacionalmente, o Barômetro da Sustentabilidade (BS) e o Painel da Sustentabilidade (PS). Além disso, pretende-se testar se essas ferramentas produzem resultados semelhantes e assim discutir sobre as oportunidades e limitações que cada um apresenta em avaliar a sustentabilidade num contexto urbano/metropolitano na região amazônica.

Dentre os diversos instrumentos para avaliação da sustentabilidade disponíveis na literatura local e internacional, optou-se por estes dois instrumentos, BS e PS, por serem ferramentas bem conhecidas pela 
comunidade científica internacional (ISSD, 2001; PRESCOTT-ALLEN, 2001). Além disso, ambas as ferramentas, apesar das singularidades inerentes a cada uma, conseguem apresentar de maneira simples e dinâmica a complexidade da realidade e das dimensões da sustentabilidade, em um formato visualmente envolvente, altamente comunicativo e fácil de ser entendido tanto por especialistas e tomadores de decisão, quanto pela sociedade em geral.

\section{MATERIAIS E MÉTODOS}

\section{Características da Área de Estudo}

A região metropolitana de Belém foi instituída em 1973, formada apenas pelos municípios de Belém e Ananindeua. Posteriormente, os outros municípios (Marituba, Benevides, Santa Isabel do Pará, Santa Bárbara do Pará e Castanhal) foram incorporados à metrópole. A área mais densamente ocupada corresponde aos municípios de Belém e Ananindeua, que já apresentam forte conurbação. O município de Marituba também já apresenta uma conurbação recente com o município de Ananindeua.

A metrópole está localizada dentro do 'Centro de Endemismo Belém', que compreende uma região entre os estados do Maranhão e Pará, com ocupação antiga e considerada a mais desmatada da Amazônia brasileira, com apenas $23 \%$ da cobertura vegetal remanescente (ALMEIDA et al., 2010). Embora grande parte da vegetação original da RMB tenha sido alterada (AMARAL et al., 2012), ainda é possível encontrar fragmentos de vegetação intacta , tais como nos municípios de Santa Bárbara do Pará, Benevides, Marituba e também em partes da região insular de Belém e Ananindeua (LIMA et al., 2009).

A metrópole de Belém possui a maior concentração de domicílios em situação de favelização do Brasil $(52,5 \%)$, sendo que Marituba é o município metropolitano brasileiro com a maior taxa de aglomerados subnormais, cerca de 77\% (IBGE, 2010). Além disso, a metrópole também apresenta baixa cobertura dos serviços de saneamento básico, como abastecimento de água e esgotamento sanitário, e infraestrutura urbana precária.

\section{Método do Barômetro da Sustentabilidade e Painel da Sustentabilidade}

Desde a Conferência das Nações Unidas sobre o Meio Ambiente e Desenvolvimento na cidade do Rio de Janeiro em 1992, diversos indicadores, índices e modelos de métrica da sustentabilidade vêm sendo desenvolvidos, com o objetivo de mensurar o grau de desenvolvimento sustentável. A escolha sobre qual sistema de indicadores ou qual ferramenta de avaliação utilizar irá depender dos objetivos a que se pretende alcançar.

Neste trabalho, para fazer a análise da sustentabilidade dos municípios da RMB, foram utilizadas duas ferramentas: Barômetro da Sustentabilidade (BS) e Painel da Sustentabilidade (PS). O BS foi desenvolvido pelo pesquisador Prescott-Allen (2001) com o apoio do International Union for Conservation of Nature and Natural Resources (IUCN) e do International Development Research Center (IDRC). É um método de análise bidimensional, composto por dois índices: Bem-Estar Humano e Bem-Estar Ambiental (VAN BELLEN, 2004). 
A metodologia para a construção do BS é simples e bastante flexível em relação ao número de indicadores, uma vez que não exige uma quantidade pré-fixada (KRONEMBERGER et al., 2004). Sendo assim, a escolha dos indicadores para a sua composição é feita de acordo com as características e o contexto da unidade a qual se pretende avaliar. Na Amazônia, essa ferramenta já vem sendo utilizada no âmbito do projeto INCT Biodiversidade e Uso da Terra para avaliar a sustentabilidade dos municípios (CARDOSO et al., 2014; 2016; LAMEIRA et al., 2015) e assentamentos rurais (SILVA et al., 2016).

O Painel da sustentabilidade é um instrumento de comparação da sustentabilidade, muito utilizado pela comunidade científica internacional, principalmente para comparar a performance de diferentes países em relação à sustentabilidade. Além disso, segundo Van Bellen (2004), pode ser aplicado também em contextos urbanos e regionais.

A ferramenta foi criada ainda no final da década de 90, pela Consultative Group on Sustainable Development Indicator (CGSDI) em parceria com outras instituições. O sistema tem como principal objetivo fazer uma análise integrada dos pilares da sustentabilidade, representados por quatro dimensões: ambiental, social, econômico e institucional. Essa ferramenta conta com uma apresentação gráfica altamente comunicativa, o que facilita a compreensão dos resultados por parte da comunidade em geral (VAN BELLEN, 2004). O formato apresentado pelo sistema é uma metáfora de um painel de automóvel, cujo ponteiro indica o grau de sustentabilidade. O PS tem como resultado final um índice (Sustainable Development Index - SDI) que é resultado da agregação de vários indicadores. Esses indicadores são combinados em dimensões gerando quatro índices: ambiental, social, econômico e institucional. A partir das médias destes índices dimensionais, obtêm-se o índice final, que é o SDI.

\section{Coleta de dados e construção do sistema de indicadores}

Para construir e calcular os índices de sustentabilidade, do Barômetro da Sustentabilidade e do Painel da Sustentabilidade dos municípios da RMB, foi necessário, primeiramente, estabelecer indicadores relevantes. Segundo Van Bellen (2004), indicadores de sustentabilidade simplificam fenômenos complexos em relação a diversas esferas referentes ao desenvolvimento sustentável, transformando esse conceito abstrato em dados quantitativos e medidas descritivas, de forma a orientar o processo de desenvolvimento sustentável.

A partir de uma pesquisa bibliográfica, foram identificados os indicadores que melhor representassem o contexto urbano/metropolitano. Esses indicadores foram definidos segundo a disponibilidade de dados para compor as quatro dimensões da sustentabilidade consideradas neste estudo: ambiental, social, econômica e institucional; e também, no caso do BS, de acordo com a viabilidade de se construir escalas de desempenho. Para cada tema que compõem os índices inseriu-se o máximo de indicadores possíveis, pois quanto mais robusto for o conjunto de indicadores menor será o efeito individual de cada um em seu respectivo tema (KRONEMBERG et al., 2008).

Os indicadores foram obtidos de fontes oficiais, como instituições e órgãos governamentais. A maioria das variáveis utilizadas na construção dos indicadores foi obtida do Instituto Brasileiro de Geografia 
e Estatística, cujo último censo foi em 2010. Dessa forma, o ano base utilizado na avaliação é o ano de 2010. Entretanto, quando não foi possível encontrar dados para esse período, utilizou-se de anos próximos.

No total foram utilizados 45 indicadores, tanto no Barômetro da Sustentabilidade quanto no Painel da Sustentabilidade, divididos em 4 dimensões: 8 na dimensão ambiental, 25 na dimensão social, 5 econômicos e 7 institucionais. Foram utilizados os mesmos indicadores em ambos os sistemas para que fosse possível fazer a comparação dos resultados dos índices. Os quadros 1, 2, 3 e 4 mostram a divisão do sistema de indicadores em quatro dimensões, subdivididas em temas com os seus indicadores correspondentes. A divisão em temas corresponde apenas ao BS, já que o PS é constituído apenas pelos indicadores e dimensões.

Quadro 1: Temas, indicadores, fontes e referências para construção das escalas de desempenho dos indicadores ambientais da região metropolitana de Belém.

\begin{tabular}{|c|c|c|c|}
\hline \multicolumn{4}{|c|}{ Dimensão Ambiental } \\
\hline TEMAS & INDICADORES & FONTE/ANO & $\begin{array}{l}\text { Referência para a construção das EDI (Barômetro da Sustentabilidade - } \\
\text { BS) }\end{array}$ \\
\hline \multirow{3}{*}{$\begin{array}{l}\text { Saneament } \\
\text { o }\end{array}$} & $\begin{array}{c}\text { Acesso à coleta regular de resíduos sólidos } \\
(\%) .\end{array}$ & \multirow{3}{*}{ IBGE (2010a). } & \multirow{3}{*}{ Considerou-se sustentável uma cobertura de $100 \%$ desses serviços. } \\
\hline & Abastecimento de água-Rede geral (\%). & & \\
\hline & $\begin{array}{c}\text { Instalação sanitária adequada (rede } \\
\text { geral e fossa séptica) (\%). }\end{array}$ & & \\
\hline Terra & Desmatamento acumulado até 2010 (\%). & INPE (2010). & $\begin{array}{l}\text { Como parâmetro, utilizou-se o limite de } 50 \% \text { de área desmatada em } \\
\text { relação à área de vegetação original (excluindo hidrografia e área de não } \\
\text { floresta) como sustentável (Código Florestal Brasileiro de 2012). }\end{array}$ \\
\hline $\begin{array}{l}\text { Qualidade } \\
\text { do ar }\end{array}$ & Número de veículos por 1000 habitantes. & $\begin{array}{l}\text { DENATRAN } \\
\text { (2010). }\end{array}$ & $\begin{array}{l}\text { O indicador é utilizado como proxy de qualidade do ar, uma vez que essa } \\
\text { é uma das principais causas de poluição atmosférica em áreas urbanas } \\
\text { (BRAGA et al., 2001). Como parâmetro foram utilizados os menores e } \\
\text { maiores valores das maiores cidades do país. }\end{array}$ \\
\hline \multirow{3}{*}{$\begin{array}{l}\text { Condições } \\
\text { Ambientais } \\
\text { urbanas }\end{array}$} & Arborização (\%). & \multirow{3}{*}{ IBGE (2010a). } & \multirow{3}{*}{$\begin{array}{l}\text { Os indicadores expressam porcentagem de domicílios em que existe } \\
\text { arborização, lixo acumulado nos logradouros e esgoto a céu aberto no seu } \\
\text { entorno. Como parâmetro considerou-se os melhores e os piores } \\
\text { desempenhos dentre as } 15 \text { maiores cidades do país (IBGE, 2010b). }\end{array}$} \\
\hline & Lixo acumulado nas ruas (\%). & & \\
\hline & Esgoto a céu aberto (\%). & & \\
\hline
\end{tabular}

Quadro 2: Temas, indicadores, fontes e referências para construção das escalas de desempenho dos indicadores sociais da região metropolitana de Belém.

\begin{tabular}{|c|c|c|c|}
\hline \multicolumn{4}{|c|}{ Dimensão Social } \\
\hline TEMAS & INDICADORES & $\begin{array}{l}\text { FONTE } \\
\text { /ANO }\end{array}$ & $\begin{array}{l}\text { Referência para a construção das EDI } \\
\text { (Barômetro da Sustentabilidade - BS) }\end{array}$ \\
\hline População & Taxa de crescimento populacional (2000-2010). & IBGE (2010a). & $\begin{array}{l}\text { Como referência considerou-se "baixo" } \\
\text { valores entre } 0 \text { a } 1,5 \% \text {; "médio" entre } \\
1,5 \% \text { a } 3 \% \text {; e "alto" valores > } 3 \% \text {. (IBGE, } \\
2010 \text { ). }\end{array}$ \\
\hline \multirow{5}{*}{ Saúde } & Leitos hospitalares ( $\mathrm{n}-/ 1.000$ habitantes). & \multirow{5}{*}{ DATASUS (2010). } & $\begin{array}{l}\text { Considerou-se como sustentável de } 2,5 \text { a } \\
3 \text { leitos hospitalares para cada } 1.000 \\
\text { habitantes (Ministério da Saúde). }\end{array}$ \\
\hline & Número de médicos (no/ 1.000 habitantes). & & $\begin{array}{l}\text { Considerou-se como sustentável os } \\
\text { valores } \geq 2,7 \text { médicos para cada } 1000 \\
\text { habitantes (Ministério da Saúde). }\end{array}$ \\
\hline & Unidades de Saúde (no/10 mil habitantes). & & $\begin{array}{l}\text { Considerou-se como referência valores } \\
\text { entre } 0 \text { a } 2,2 \text { (baixo) e maior que } 10,2 \\
\text { (elevado) (OMS). }\end{array}$ \\
\hline & Mortalidade Materna (n/ 100 mil habitantes). & & $\begin{array}{l}\text { Considerou-se como referência os } \\
\text { valores: baixa (abaixo de } 20 \text { por } 100 \text { mil), } \\
\text { média ( } 20 \text { a } 49 \text { por } 100 \text { mil) alta ( } 50 \text { a } 149 \\
\text { por } 100 \text { mil) e muito alta (maior que } 150 \\
\text { mil) (OMS). }\end{array}$ \\
\hline & Mortalidade Infantil (no/ 1000 nascidos vivos). & & $\begin{array}{l}\text { Considerou-se como referência os } \\
\text { valores iguais a } 50 \text { ou mais (altas); entre } \\
20-49 \text { (médias); e entre menos de } 20 \\
\text { (baixas) (OMS). }\end{array}$ \\
\hline \multirow{4}{*}{ Educação } & Analfabetismo (\%). & IBGE (2010a). & $\begin{array}{l}\text { Como referência considerou-se } \\
\text { sustentável a erradicação do } \\
\text { analfabetismo (ODS, 2015). }\end{array}$ \\
\hline & $\begin{array}{c}\text { IDEB. } \\
\text { (séries iniciais) }\end{array}$ & \multirow{2}{*}{ INEP (2013). } & \multirow{2}{*}{$\begin{array}{l}\text { Como referência considerou-se como } \\
\text { sustentável as notas } \geq 6 \text {, e como } \\
\text { intermediário as metas estabelecidas } \\
\text { para o estado do Pará: } 3,7 \text { para séries } \\
\text { iniciais e } 4,0 \text { para séries finais. }\end{array}$} \\
\hline & IDEB (séries finais). & & \\
\hline & Acesso à Creche (\%). & IBGE (2010a). & $\begin{array}{l}\text { Porcentagem de crianças de } 0 \text { a } 3 \text { anos } \\
\text { que frequentam escola ou creche. } \\
\text { Considerou-se sustentável a meta }\end{array}$ \\
\hline
\end{tabular}




\begin{tabular}{|c|c|c|c|}
\hline & & & $\begin{array}{l}\text { estabelecida pelo Plano Nacional de } \\
\text { Educação-PNE, que é ampliar o número } \\
\text { de oferta de vagas em creches para } \\
\text { atender no mínimo } 50 \% \text { dessas crianças. }\end{array}$ \\
\hline & Acesso à Pré-escola (\%). & & $\begin{array}{l}\text { O indicador expressa a porcentagem de } \\
\text { crianças de } 4 \text { a } 5 \text { anos que frequentam } \\
\text { escola ou creche. Considerou-se } \\
\text { sustentável a meta segundo o PNE, que é } \\
\text { universalizar a educação infantil na pré- } \\
\text { escola para crianças nessa faixa etária. }\end{array}$ \\
\hline & Taxa de escolarização (6-14 anos) (\%). & & $\begin{array}{l}\text { O indicador expressa a quantidade de } \\
\text { crianças de } 6 \text { a } 14 \text { anos que frequentam } \\
\text { a escola. Considerou-se sustentável a } \\
\text { meta segundo o PNE, que é universalizar } \\
\text { o Ensino Fundamental de } 9 \text { anos para } \\
\text { toda a população de } 6 \text { a } 14 \text { anos }\end{array}$ \\
\hline & Taxa de escolarização (15-17 anos) (\%). & & $\begin{array}{l}\text { O indicador mede o percentual de jovens } \\
\text { de } 15 \text { a } 17 \text { anos que estão na escola, } \\
\text { independentemente de estarem } \\
\text { cursando o ano compatível com a sua } \\
\text { idade. Considerou-se sustentável a meta } \\
\text { do PNE que é universalizar o } \\
\text { atendimento escolar para toda a } \\
\text { população de } 15 \text { a } 17 \text { anos. }\end{array}$ \\
\hline & Taxa de Distorção Idade-Série - Ensino Fundamental (\%). & & O indicador expressa a porcentagem de \\
\hline & Taxa de Distorção Idade-Série - Ensino Médio (\%). & INEP (2010). & $\begin{array}{l}\text { alunos que estão com defasem entre } \\
\text { idade e série. Como referência } \\
\text { considerou-se a meta do PNE que } \\
\text { estabelece que } 95 \% \text { dos alunos devem } \\
\text { concluir o ensino fundamental com a } \\
\text { idade adequada ( } 16 \text { anos) e que } 85 \% \text { dos } \\
\text { alunos estejam matriculados no ensino } \\
\text { médio com a idade correta. }\end{array}$ \\
\hline \multirow{5}{*}{ Equidade } & Índice de Gini (2010). & \multirow{4}{*}{ IBGE (2010a). } & $\begin{array}{l}\text { O indicador expressa a desigualdade na } \\
\text { distribuição de renda. Quanto mais } \\
\text { próximo de } 1 \text {, maior a desigualdade e } \\
\text { quanto mais próximo de } 0 \text { menor é. }\end{array}$ \\
\hline & Razão de rendimento por sexo (mulher/homem). & & \multirow{3}{*}{$\begin{array}{l}\text { O ideal é a razão igual a } 1 \text {, que representa } \\
\text { igualdade de rendimento. Quanto mais } \\
\text { próximo de } 1 \text {, maior a igualdade e quanto } \\
\text { mais próximo de } 0 \text { menor é. }\end{array}$} \\
\hline & Razão de rendimento por cor ou raça (negros / brancos). & & \\
\hline & Razão de rendimento por cor ou raça (pardos / brancos). & & \\
\hline & Participação feminina (\%). & TSE (2012). & $\begin{array}{l}\text { O indicador expressa a presença } \\
\text { feminina na política. Foi calculado a } \\
\text { partir da porcentagem de mulheres } \\
\text { eleitas vereadoras em relação ao total de } \\
\text { vereadores eleitos no ano de referência } \\
\text { de } 2012 \text { Considerou-se como } \\
\text { sustentável a paridade ( } 50 \% \text { ). }\end{array}$ \\
\hline \multirow[b]{2}{*}{ Segurança } & Coeficiente de mortalidade por acidentes de transporte ( $\mathrm{n}-/ 100$ mil habitantes). & \multirow[b]{2}{*}{ DATASUS (2010). } & \multirow{2}{*}{$\begin{array}{l}\text { Como referência considerou-se os } \\
\text { menores e maiores valores dos } \\
\text { municípios do Estado do Pará. }\end{array}$} \\
\hline & Coeficiente de mortalidade por homicídios (no/100 mil habitantes). & & \\
\hline \multirow{3}{*}{ Habitação } & Aglomerados subnormais (\%). & \multirow{3}{*}{ IBGE (2010a). } & $\begin{array}{l}\text { O indicador expressa a quantidade de } \\
\text { domicílios localizados em aglomerados } \\
\text { subnormais, ou seja, em situação } \\
\text { precária de habitabilidade. Considerou- } \\
\text { se como sustentável a inexistência } \\
\text { desses aglomerados. }\end{array}$ \\
\hline & Adensamento excessivo (\%). & & $\begin{array}{l}\text { O indicador expressa a porcentagem de } \\
\text { domicílios com densidade acima de } 2 \\
\text { moradores por dormitório. Considerou- } \\
\text { se como sustentável que } 100 \% \text { dos } \\
\text { domicílios tenham uma densidade de até } \\
2 \text { moradores por dormitório (IBGE, 2015) }\end{array}$ \\
\hline & Acesso à energia elétrica (\%). & & $\begin{array}{l}\text { O indicador expressa a porcentagem de } \\
\text { domicílios com acesso à energia elétrica. } \\
\text { Considerou-se como sustentável uma } \\
\text { cobertura de } 100 \% \text {, por se tratar de um } \\
\text { serviço essencial. }\end{array}$ \\
\hline
\end{tabular}

Quadro 3: Temas, indicadores, fontes e referências para construção das escalas de desempenho dos indicadores econômicos da região metropolitana de Belém.

\begin{tabular}{|c|c|c|c|}
\hline \multicolumn{4}{|c|}{ Dimensão Econômica } \\
\hline TEMAS & INDICADORES & FONTE /ANO & $\begin{array}{c}\text { Referência para a construção das EDI (Barômetro da Sustentabilidade } \\
\text { - BS) }\end{array}$ \\
\hline Quadro Econômico & $\begin{array}{l}\text { PIB per capta } \\
\text { (R\$) }\end{array}$ & $\begin{array}{l}\text { IBGE - Censo Demográfico } \\
2010 a\end{array}$ & $\begin{array}{l}\text { Como referência considerou-se os menores e maiores PIBs dos } \\
\text { municípios do estado do Pará. Valores acima de } R \$ 19.000 \text { foram } \\
\text { considerados sustentáveis. }\end{array}$ \\
\hline $\begin{array}{l}\text { Trabalho e } \\
\text { Rendimento }\end{array}$ & $\begin{array}{l}\text { Renda per capta } \\
\text { (R\$) }\end{array}$ & $\begin{array}{l}\text { IBGE - Censo Demográfico } \\
\text { 2010a }\end{array}$ & $\begin{array}{l}\text { Como referência considerou-se sustentáveis valores entre } \mathrm{R} \$ 624,00 \text { a } \\
\mathrm{R} \$ 1.157,00 \text { (PNUD) }\end{array}$ \\
\hline
\end{tabular}




\begin{tabular}{|c|c|c|}
\hline & $\begin{array}{l}\text { Extrema pobreza } \\
\qquad(\%)\end{array}$ & $\begin{array}{l}\text { Porcentagem da população com renda per capta mensal abaixo de } \mathrm{R} \$ 70 \text {. } \\
\text { Como parâmetro considerou-se a meta de erradicação da pobreza (ODS, } \\
\text { 2015). }\end{array}$ \\
\hline & $\begin{array}{l}\text { Taxa de Desocupação } \\
(\%)\end{array}$ & $\begin{array}{l}\text { Porcentagem da população de } 10 \text { ou mais anos de idade que se } \\
\text { encontrava desempregada na semana de referência. Como parâmetro, } \\
\text { consideraram-se as melhores e piores taxas do Brasil. }\end{array}$ \\
\hline & $\begin{array}{l}\text { Trabalho Infantil } \\
\qquad(\%)\end{array}$ & $\begin{array}{l}\text { Porcentagem da população de } 10 \text { a } 15 \text { anos de idade trabalhando ou } \\
\text { procurando trabalho na semana de referência. Considerou-se como } \\
\text { parâmetro a erradicação do trabalho infantil (ODS, 2015). }\end{array}$ \\
\hline
\end{tabular}

Quadro 1 - Temas, indicadores, fontes e referências para construção das escalas de desempenho dos indicadores institucionais da região metropolitana de Belém.

\begin{tabular}{|c|c|c|c|}
\hline \multicolumn{4}{|c|}{ Dimensão Institucional } \\
\hline TEMAS & INDICADORES & FONTE/ ANO & $\begin{array}{c}\text { Referência para a construção das EDI (Barômetro da } \\
\text { Sustentabilidade - BS) }\end{array}$ \\
\hline \multirow{4}{*}{$\begin{array}{l}\text { Quadro } \\
\text { Institucional }\end{array}$} & Legislação ambiental & $\begin{array}{l}\text { IBGE - Perfil dos } \\
\text { Municípios } \\
\text { Brasileiros (2012) }\end{array}$ & $\begin{array}{l}\text { O indicador expressa se o município possui legislação específica para } \\
\text { tratar das questões ambientais municipais. O critério utilizado foi } 1 \\
\text { para respostas afirmativas (sustentável) e } 0 \text { para respostas } \\
\text { negativas (insustentável). }\end{array}$ \\
\hline & Conselhos municipais ativos (\%) & $\begin{array}{l}\text { IBGE - Perfil dos } \\
\text { Municípios } \\
\text { Brasileiros (2011; } \\
\text { 2012) }\end{array}$ & $\begin{array}{l}\text { O indicador foi construído a partir de respostas positivas para a } \\
\text { existência ou não de conselhos municipais ativos (com reunião do } \\
\text { conselho nos últimos } 12 \text { meses do ano em questão) na área de } \\
\text { saúde, meio ambiente, habitação, educação, meio ambiente. } \\
\text { Considerou-se sustentável o máximo de respostas positivas. }\end{array}$ \\
\hline & Participação em Comitês de Bacias Hidrográficas & $\begin{array}{l}\text { IBGE - Perfil dos } \\
\text { Municípios } \\
\text { Brasileiros (2012) }\end{array}$ & $\begin{array}{l}\text { O indicador expressa se o município faz parte de Comitês de Bacias } \\
\text { Hidrográficas. O critério utilizado foi } 1 \text { para respostas afirmativas } \\
\text { (sustentável) e } 0 \text { para respostas negativas (insustentável). }\end{array}$ \\
\hline & $\begin{array}{l}\text { Organizações da sociedade civil } \\
\text { (no FASFIL/ } 100 \text { mil hab.) }\end{array}$ & $\begin{array}{l}\text { IBGE - Fundações } \\
\text { Privadas e } \\
\text { Associações Sem } \\
\text { Fins Lucrativos } \\
\text { (2010) }\end{array}$ & $\begin{array}{l}\text { O indicador apresenta o número de Fundações Privadas e } \\
\text { Associações Sem Fins Lucrativos - FASFIL existentes no município } \\
\text { para cada } 100 \text { mil habitantes. Como parâmetros consideraram-se os } \\
\text { menores e maiores valores do estado do Pará. }\end{array}$ \\
\hline \multirow[t]{3}{*}{$\begin{array}{l}\text { Capacidade } \\
\text { Institucional }\end{array}$} & Articulação interinstitucional (\%) & $\begin{array}{l}\text { IBGE - Perfil dos } \\
\text { Municípios } \\
\text { Brasileiros (2011) }\end{array}$ & $\begin{array}{l}\text { O indicador representa o total de articulações interinstitucionais } \\
\text { que o município possui em relação ao total de articulações possíveis } \\
\text { (88). Foram consideradas } 8 \text { tipos de articulação interinstitucional } \\
\text { (consórcio público intermunicipal; consórcio público com o estado; } \\
\text { consórcio público com o governo federal; consórcio administrativo } \\
\text { intermunicipal; consórcio administrativo com o estado; consórcio } \\
\text { administrativo com o governo federal; convênio de parceria com o } \\
\text { setor privado; e apoio do setor privado ou de comunidades) em } 11 \\
\text { áreas de atuação administrativa (Educação, Saúde, Assistência e } \\
\text { desenvolvimento social, Emprego e/ou Trabalho, Turismo, Cultura, } \\
\text { Habitação, Meio Ambiente, Transporte, Desenvolvimento urbano, } \\
\text { Saneamento Básico). Considerou-se como sustentável o máximo de } \\
\text { articulações possíveis, tendo como parâmetro os valores dos } \\
\text { estados do Brasil (IBGE, 2015). }\end{array}$ \\
\hline & Existência de fundo municipal de meio ambiente & $\begin{array}{l}\text { IBGE - Perfil dos } \\
\text { Municípios } \\
\text { Brasileiros (2012) }\end{array}$ & O indicador considerou sim (1) sustentável e não (0) insustentável. \\
\hline & Acesso à internet (\%) & $\begin{array}{l}\text { IBGE - Censo } \\
\text { Demográfico } \\
\text { 2010a }\end{array}$ & $\begin{array}{l}\text { Percentual de domicílios com acesso à internet. Considerou-se } \\
\text { sustentável uma cobertura universal de Internet (100\%). }\end{array}$ \\
\hline
\end{tabular}

\section{Metodologia de cálculo: normatização dos dados}

Como os indicadores selecionados possuem unidades diferentes, e para que sejam agregados em índices é necessário padronizá-los. Para isso foram utilizadas as ferramentas Barômetro da SustentabilidadeBS e Painel da Sustentabilidade (PS). A metodologia para a construção do BS consiste em, primeiramente, elaborar as escalas de desempenho dos indicadores. Para isso é necessário adotar valores de referências nacionais ou globais existentes ou determinados de acordo com a literatura, que sirvam de base para construção dessas escalas. Segundo Van Bellen (2004), esses valores podem ser metas numéricas ou padrões existentes do que seja sustentável ou não.

A partir desses valores são definidos os limites da escala de desempenho para cada indicador (EDI), que correspondem aos intervalos da escala do BS (EBS), que varia 0 a 100. Os intervalos são: 0-20 (Insustentável), 21-40 (Potencialmente Insustentável), 41-60 (Intermediário), 61-80 (Potencialmente Sustentável) e 81-100 (Sustentável) (KRONEMBERGER et al.; CLEVELÁRIO JÚNIOR, 2004). Após definir e 
elaborar a escalas de desempenho para cada um dos 45 indicadores utilizados nesse trabalho foi feita a transposição desses valores para o EBS. Essa transposição foi feita através de uma interpolação linear

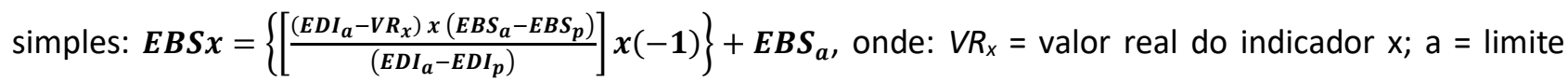
anterior do intervalo que contém $V R_{x}$; e $\mathrm{p}=$ limite posterior do intervalo que contém $V R_{x}$.

Já com os cálculos individuais de cada indicador na escala do BS, esses foram agregados hierarquicamente. Primeiramente, obteve-se a média aritmética dos indicadores de cada tema, e então, calculou-se um índice para cada dimensão (ambiental, social, econômica e institucional) através da média aritmética dos temas correspondentes. Por último, calculou-se dois índices para cada município da região metropolitana de Belém, correspondentes aos subsistemas sociedade e natureza: Índice de Bem-Estar Humano e Índice de Bem-Estar Ambiental.

Para calcular o índice do Painel da Sustentabilidade dos municípios da RMB, os indicadores foram padronizados através do software do PS, versão 50.4 de 2 de janeiro de 2012. Este software é um protótipo do índice criado pelo CGSDI. Essa ferramenta atribui uma pontuação que varia entre 0 (pior situação) a 1000 (melhor situação) para cada indicador, de acordo com a fórmula: (Score PS) $=1000^{*}[(x-w) /(b-w)]$, onde $x$ é o valor do indicador; w (worst - pior) é o pior caso; e b (best - melhor) é o melhor caso para aquele determinado indicador (SCIPIONI et al., 2009). A ferramenta permite a utilização de pesos para os indicadores, mas nesta pesquisa não foi adotada.

Após padronizar cada indicador, é calculado um índice para cada aspecto: Ambiental, Econômico, Social e Institucional. Esses índices são calculados a partir da média da pontuação do PS de todos os indicadores de cada grupo. Por último é então calculado um índice geral (Índice de Desenvolvimento Sustentável - IDS), a partir da média dos quatro índices dimensionais. Este índice geral, ou seja, a evolução da performance numérica é associada à uma escala de cores: tons de verde (melhores performances), amarelo (médio) e tons de vermelho (piores performances).

Esse sistema é bem flexivo, permitindo modificações e adaptações no número de indicadores e nas dimensões. Além disso, através do seu sistema eletrônico é possível fazer a análise dos dados e resultados em diversos formatos, como mapas, imagens, fluxogramas, gráficos entre outros. Para analisar a similaridade entre os municípios, com relação aos indicadores usados, sem considerar previamente suas propriedades ou características, foi realizada uma análise de agrupamento multivariada.

O método empregado para gerar os algoritmos responsáveis pelos agrupamentos foi o coeficiente de correlação. Neste caso, quanto maior for a medida de similaridade maior semelhança entre os municípios. A forma gráfica da análise é exposta em forma de dendrograma. Neste caso, os grupos são figurados em forma de árvore, e examina-se visualmente a disposição do gráfico para busca de padrões.

\section{RESULTADOS}

\section{Barômetro da Sustentabilidade}

Os resultados obtidos com o método do barômetro da sustentabilidade geraram dois índices numéricos, índice de bem-estar humano e índice de bem-estar ambiental, para cada município da região 
metropolitana de Belém. Estes resultados foram plotados em um gráfico bidimensional, cuja posição revela o grau de sustentabilidade de cada município, conforme se vê na figura 1.0 índice de bem-estar humano é representado pela média das dimensões social, econômica e institucional. Já o índice de bem-estar ambiental é representado pelo grau obtido na dimensão ambiental.

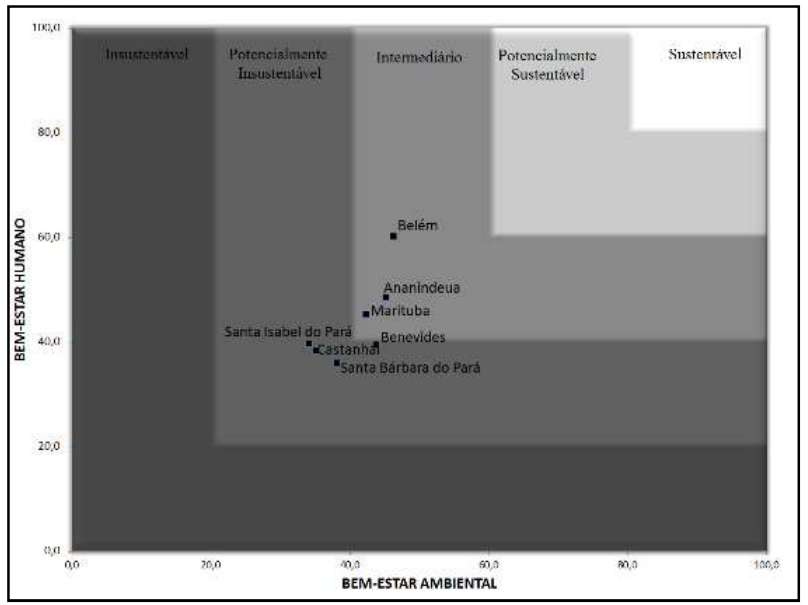

Figura 1: Sustentabilidade dos municípios da região metropolitana de Belém, segundo o Barômetro da Sustentabilidade.

De modo geral, os municípios da RMB apresentaram dois níveis de sustentabilidade: intermediário e potencialmente insustentável. Os melhores desempenhos foram apresentados pelos municípios de Belém, Ananindeua e Marituba, com um nível intermediário de sustentabilidade. Já os municípios de Benevides, Castanhal, Santa Bárbara do Pará e Santa Isabel do Pará, encontram-se em um nível 'potencialmente insustentável', como demonstra a figura 1.

O Índice de Bem-Estar Humano - BEH é resultado da avaliação de trinta e sete indicadores agregados em dez temas (População, Saúde, Educação, Equidade, Segurança, Habitação, Quadro Econômico, Trabalho e Rendimento, Quadro Institucional, e Capacidade Institucional). Estes temas estão subdivididos em três dimensões: Social, Econômica e Institucional. Nas três dimensões do índice BEH, o município de Belém apresentou os melhores desempenhos (tabela 1).

Tabela 1: Nível de sustentabilidade dos municípios da região metropolitana de Belém por dimensão, segundo o Barômetro da Sustentabilidade.

\begin{tabular}{|c|c|c|c|c|}
\hline \multirow{2}{*}{ Municípios da região metropolitana de Belém } & \multicolumn{4}{|c|}{ Dimensões } \\
\hline & Ambiental & Social & Econômica & Institucional \\
\hline Belém & 46,3 & 53,3 & 55,2 & 72,1 \\
\hline Ananindeua & 45,2 & 43,6 & 47,3 & 54,9 \\
\hline Marituba & 42,3 & 39,8 & 39,5 & 56,6 \\
\hline Benevides & 43,9 & 44,2 & 47,7 & 26,8 \\
\hline Santa bárbara do Pará & 38,2 & 47,8 & 31,4 & 29,1 \\
\hline Santa Isabel do Pará & 34,1 & 40,6 & 38,6 & 39,7 \\
\hline Castanhal & 35,1 & 45,4 & 47,3 & 22,2 \\
\hline
\end{tabular}

Legenda: Entre 0-20 (Insustentável); 21-40 (Potencialmente Insustentável); 41-60 (Intermediário); 61-80 (Potencialmente Sustentável); e 81-100 (Sustentável).

Já o índice BEA, representado pelo grau obtido na dimensão ambiental, é resultado da avaliação de oito indicadores, divididos em quatro temas (Saneamento, Terra, Qualidade do Ar e Condições Ambientais Urbanas). Para este índice, as melhores performances ocorreram nos municípios de Belém, Ananindeua, 
Benevides e Marituba, classificados como 'intermediário'. Apesar do município de Belém apresentar a melhor performance, pouco se diferencia dos demais classificados nesse mesmo nível. O pior resultado foi apresentado pelo município de Santa Isabel do Pará, juntamente com os municípios de Castanhal e Santa Bárbara do Pará, todos em uma situação de 'potencialmente insustentável' (tabela 01).

\section{Painel da Sustentabilidade}

A aplicação do Painel da Sustentabilidade à região metropolitana de Belém resultou em um índice sintético na forma numérica (Índice de Desenvolvimento Sustentável (IDS), em inglês Sustainable Development Index - SDI) e gráfica para cada município. O IDS é resultado da média das quatro dimensões (ambiental, social, econômica e institucional) estimadas no PS, o qual indica através de um índice sintético o desempenho municipal. Dessa forma, a partir do score atribuído a cada indicador com base em seus valores reais, estes foram classificados em nove intervalos de uma escala numérica que varia de 0 a 1000, associada a uma escala de cores que vai do vermelho escuro (pior desempenho) ao verde escuro (melhor desempenho). No entanto, neste trabalho essa escala colorida foi substituída por uma escala de cinza, em que o 'pior desempenho' é representado pela parte mais escura e o 'melhor desempenho' pela parte mais clara.

A figura 2 mostra o produto final da aplicação do PS, o qual gerou sete painéis correspondentes a cada município da RMB. Esses painéis demostram a performance dos municípios em relação ao IDS, indicada pela posição de um ponteiro, semelhante a 'um velocímetro de carro'. Cada painel também contém quatro círculos que correspondem ao desempenho de cada município em relação às dimensões que compõem o índice.

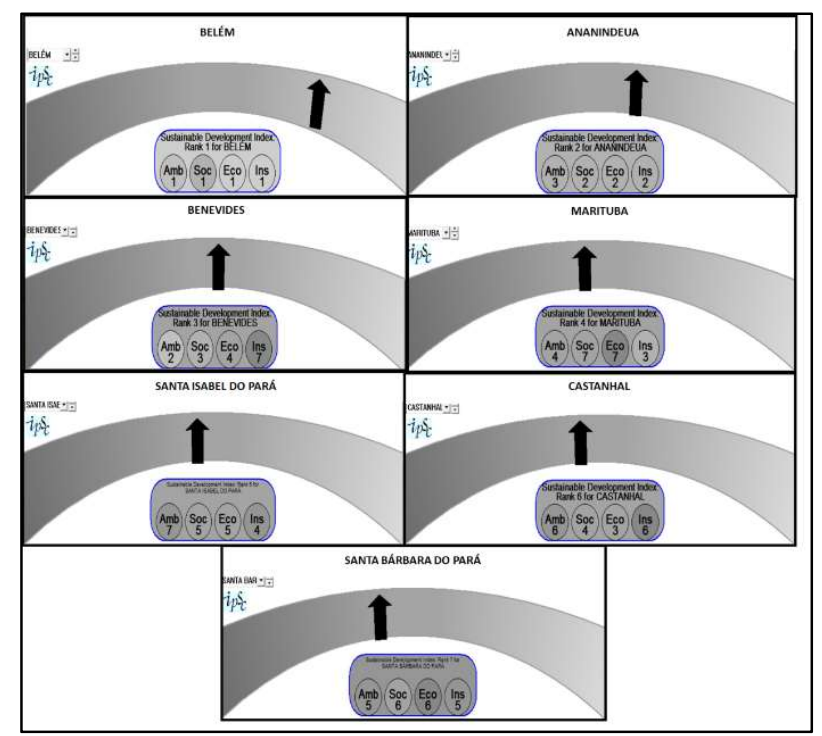

Figura 2: Índice de Desenvolvimento Sustentável dos municípios da região metropolitana de Belém, segundo o Painel da Sustentabilidade. Legenda: A pior performance, 'estado crítico', é representada pela parte mais escura, e a 'melhor performance', 'excelente', pela parte mais clara.

Em geral, o IDS dos municípios que compõem a RMB variou de 'ruim' a 'muito bom'. No ranking do IDS para a RMB, o município de Belém se destaca em relação aos demais, o qual obteve um desempenho 'muito bom' (780 pontos). Já o município de Santa Bárbara do Pará apresentou a pior performance, sendo classificado como 'ruim' (411 pontos). O município de Ananindeua ficou com a segunda posição no ranking, 
com uma performance "razoável" (599 pontos). Os outros municípios, Benevides (512 pontos), Marituba (460 pontos), Santa Isabel do Pará (458 pontos) e Castanhal (448 pontos), apresentaram um IDS médio, com pouca variação entre eles.

Para a dimensão ambiental, composta por 8 indicadores, as performances dos municípios variaram de 'bom' a 'ruim'. Os melhores desempenhos foram apresentados pelos municípios de Belém e Benevides (Bom), seguido pelo município de Ananindeua (Razoável). Já o pior resultado foi do município de Santa Isabel do Pará (Ruim), juntamente com os municípios de Castanhal e Santa Bárbara do Pará (Ruim). Em um nível médio de desempenho ambiental, encontra-se Marituba (tabela 2).

Na dimensão social, composta por 25 indicadores, é possível observar que, assim como no BS (Tabela 1), essa é a dimensão com a menor variação entre os municípios, sendo a maioria classificados com um desempenho médio (tabela 2). A melhor performance foi apresentada pelo município de Belém, seguido pelo município de Ananindeua e Benevides, todos classificados com um desempenho 'razoável'. Já os outros municípios, Castanhal, Santa Isabel do Pará, Santa Bárbara do Pará e Marituba foram classificados com um desempenho 'médio' para esta dimensão.

A dimensão econômica, composta por 5 indicadores, a performance dos municípios variou de 'muito bom' a 'muito ruim' (tabela 2). A melhor performance para o índice sintético desta dimensão foi o do município de Belém (Muito Bom), seguido pelo município de Ananindeua (Razoável). Os municípios de Marituba e Santa Bárbara do Pará apresentaram um desempenho 'muito ruim'. Já os municípios de Castanhal, Benevides e Santa Isabel do Pará tiveram um desempenho 'médio'.

Na dimensão institucional, composta por 7 indicadores, o desempenho dos municípios variou de 'muito bom' a 'muito ruim'. A melhor performance nesta dimensão foi do município de Belém (Muito Bom) e a pior o do município de Benevides (Muito Ruim). Os municípios de Ananindeua e Marituba foram classificados como 'razoável', e os municípios de Santa Isabel do Pará e Santa Bárbara do Pará como 'ruim' e o município de Castanhal como 'muito ruim' (tabela 2).

Tabela 2 - Desempenho dos municípios da região metropolitana de Belém em relação às dimensões ambiental, social, econômica e institucional, segundo o Painel da Sustentabilidade.

\begin{tabular}{|c|c|c|c|c|}
\hline \multirow{2}{*}{ Municípios da região metropolitana de Belém } & \multicolumn{4}{|c|}{ Dimensões } \\
\hline & Ambiental & Social & Econômica & Institucional \\
\hline BELÉM & 755 & 620 & 864 & 881 \\
\hline ANANINDEUA & 580 & 597 & 562 & 658 \\
\hline MARITUBA & 507 & 491 & 261 & 582 \\
\hline BENEVIDES & 713 & 558 & 484 & 294 \\
\hline SANTA BÁRBARA DO PARÁ & 441 & 494 & 328 & 381 \\
\hline SANTA ISABEL DO PARÁ & 439 & 524 & 461 & 408 \\
\hline CASTANHAL & 440 & 534 & 518 & 301 \\
\hline
\end{tabular}

\section{Análise Multivariada}

A figura 3 mostra a similaridade existente entre os municípios de Belém e Ananindeua separados dos demais da RMB que formam um outro bloco. Internamente, nesse grupo, existe uma separação de Marituba, e depois Santa Bárbara. Essa análise é interessante, pois mesmo sendo exploratória, também serviu para comparar os padrões observados aqui com os resultados das análises dos indicadores. Neste caso, pode-se 
observar um alto grau de correlação entre os resultados de ambas as metodologias. As características específicas de Belém e Ananindeua se destacam dos demais municípios, assim como Marituba em um segundo momento.

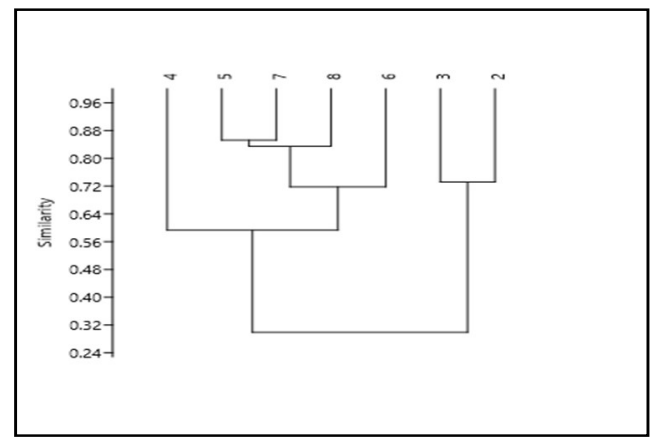

Figura 3: Análise de agrupamento multivariada para os municípios da RMB. Os números correspondem aos municípios: 2) Belém; 3) Ananindeua; 4) Marituba; 5) Benevides; 6) Santa Bárbara do Pará; 7) Santa Isabel do Pará; 8) Castanhal.

\section{DISCUSSÃO}

\section{Barômetro da Sustentabilidade}

O município de Belém foi o que apresentou a melhor performance para o índice de BEH, com um desempenho intermediário, bem próximo do nível potencialmente sustentável, seguido pelos municípios de Ananindeua e Marituba, respectivamente, em um nível intermediário. Já o pior desempenho foi do município de Santa Bárbara do Pará, classificado como potencialmente insustentável, juntamente com os municípios de Santa Isabel do Pará Castanhal e Benevides (Figura 1).

Vale ressaltar que apesar do município de Marituba apresentar um desempenho intermediário para o índice de BEH, as condições socioeconômicas do município são potencialmente insustentáveis (Tabela 1). Logo, o desempenho intermediário para este índice deve-se principalmente à dimensão institucional do município.

Houve pouca variação entre os municípios em relação à dimensão social, sendo a maioria classificada como 'intermediário', com exceção do município de Marituba, com um desempenho 'potencialmente insustentável' (Tabela 1). Embora o município de Marituba apresente um desempenho intermediário para a maioria dos temas dessa dimensão (Educação, Equidade, Segurança e Habitação), nos temas 'População' e 'Saúde' o município teve resultados críticos, com um desempenho 'insustentável' e 'potencialmente insustentável', respectivamente.

Na dimensão econômica, além do município de Belém, os municípios de Ananindeua, Castanhal e Benevides também apresentaram um desempenho intermediário. $O$ pior desempenho para esta dimensão foi apresentado pelo município de Santa Bárbara do Pará, ficando em um nível potencialmente insustentável, juntamente com os municípios de Santa Isabel do Pará e Marituba (Tabela 1). O município de Santa Bárbara do Pará teve o pior desempenho no tema 'Quadro econômico', que é representado pelo indicador 'PIB per capta' e cujo valor de R\$\$4.170,77 (IBGE, 2010) foi considerado insustentável na escala do barômetro. 
Entretanto, vale ressaltar que esse é o menor município em termos populacionais e o único ainda com predomínio da população rural, cerca de 68\%. Apesar disso, na última década teve um crescimento de 4,18\%, uma taxa bastante elevada quando comparada ao município de Belém, com 0,85\% (IBGE, 2010), o que revela uma tendência de expansão da metrópole em direção aos municípios mais periféricos.

A dimensão institucional, constituída por dois temas (Quadro Institucional e Capacidade Institucional), foi a que teve a maior variação entre os municípios, os quais foram classificados em três tipologias: potencialmente sustentável, intermediário e potencialmente insustentável (Tabela 1). O município de Belém teve a melhor classificação nessa dimensão, com um desempenho potencialmente sustentável.

No nível intermediário encontram-se os municípios de Ananindeua e Marituba. O município de Castanhal apresentou o pior desempenho para esta dimensão, classificado em um nível potencialmente insustentável juntamente com os municípios de Benevides, Santa Bárbara do Pará e Santa Isabel do Pará. O baixo desempenho institucional, para a maioria dos municípios, revela a fragilidade da metrópole em relação aos seus instrumentos políticos e legais, à participação dos segmentos da sociedade, e à capacidade institucional (tecnológica, financeira e organizacional), tão necessários para dar suporte ao desenvolvimento sustentável.

Em Belém os temas que obtiveram os melhores resultados na dimensão ambiental foram 'Qualidade do ar' e 'Saneamento', classificados como 'potencialmente sustentável' e 'intermediário', respectivamente. Embora, o resultado para o tema 'Qualidade do Ar', que é representado pelo indicador 'Número de veículos por 1000 habitantes', pareça satisfatório, o número de carros e motos tem tido um crescimento acelerado nos últimos anos na capital e sua metrópole. Esses dados até o momento não implicam na baixa qualidade do ar, de acordo com a escala do BS.

Entretanto, esse crescimento acelerado pode ter efeitos na qualidade de vida da população, com os transtornos causados pelo tempo de espera nos engarrafamentos, principalmente para quem trabalha ou estuda na capital e mora nos municípios do entorno. Já em relação ao 'Saneamento', apesar de o município apresentar o melhor resultado para esse tema em relação aos demais municípios da RMB, esse resultado foi alcançado, principalmente, em razão do indicador 'Coleta de resíduos sólidos', porém com baixo desempenho em 'Abastecimento de água' e 'Instalação sanitária adequada'.

O município de Santa Isabel do Pará foi o que obteve a pior performance geral para esta dimensão. A maioria dos indicadores teve um resultado insatisfatório. O município apresenta sérios problemas em relação ao 'Saneamento', principalmente no abastecimento de água e esgotamento sanitário adequado, e também em relação às 'Condições ambientais urbanas', com pouca arborização e presença de esgoto a céu aberto nas ruas do município. Além disso, o município apresenta umas das maiores proporções de área desmatada até o ano de 2010, atrás apenas do município de Castanhal. Essas condições estão longe do que se almeja para um ambiente equilibrado.

Em relação ao PS, o desempenho da dimensão ambiental do município de Belém (Tabela 2) é resultado principalmente dos indicadores 'Abastecimento de água', 'Instalação sanitária adequada', 
'Desmatamento', 'Arborização' e 'Esgoto a céu aberto', classificados entre 'excelente' e 'razoável'. Entretanto, apesar de esses indicadores apresentarem os melhores resultados quando comparados aos outros municípios da RMB, os indicadores estão longe de serem considerados adequados.

Na capital, apenas 75\% dos domicílios são abastecidos pela rede geral de distribuição, e 68\% contam com esgotamento sanitário adequado. Em relação às condições ambientais urbanas, a situação também não é nada satisfatória, sendo que $43 \%$ dos domicílios encontram-se em ruas com presença de esgoto a céu aberto, e somente $21 \%$ com arborização (IBGE, 2010). Além disso, apesar do município apresentar uma das menores taxas de desmatamento acumulado da RMB até o ano 2010 (INPE, 2010), evidencia-se que quase dois terços do município é constituído por uma porção insular, com baixa densidade populacional e menor desmatamento (FERREIRA et al., 2012). Logo, se fosse considerada apenas a porção continental, o resultado para esse indicador seria crítico.

No PS, o município de Belém apresentou performances classificadas como 'excelente' para 10 de seus 25 indicadores sociais. Além disso, outros 5 indicadores, tais como 'Mortalidade materna', 'Acesso à creche', 'Coeficiente de mortalidade por acidente de transporte', 'Homicídios e Taxa de escolarização (1517anos)', também apresentaram um resultado satisfatório, sendo classificados como 'bom' e 'muito bom'.

O município de Belém lidera o ranking da dimensão econômica no PS, pois dentro do contexto da RMB é o que apresenta os melhores resultados em relação à maioria dos índices. Apenas o indicador 'Trabalho Infantil' foi classificado como 'ruim'. Já o município de Marituba, assim como na dimensão social (Tabela 2) foi o que apresentou a pior situação dentre os municípios da RMB. A maioria dos indicadores tiveram uma performance insatisfatória, exceto o indicador 'Extrema pobreza', classificado como 'muito bom'.

Já para a dimensão institucional, os resultados do PS mostraram que a maioria dos indicadores dessa dimensão foi classificada como 'excelente' para o município de Belém, exceto 'Existência de Conselhos Municipais Ativos' (Bom) e Organizações da sociedade civil (Médio). Já o município de Benevides, último colocado, apenas dois indicadores tiveram um desempenho satisfatório: 'Legislação ambiental específica' (excelente) e 'Articulação Interinstitucional' (razoável).

\section{Análise Comparativa}

Os dois modelos de métrica da sustentabilidade indicaram o mesmo município, Belém, como sendo o mais sustentável. Em relação ao menos sustentável, para o PS, Santa Bárbara do Pará é o município que apresenta a pior performance. Já para o BS, como os resultados são apresentados em dois índices, somente para o índice de bem-estar humano é que Santa Bárbara do Pará apresentou a pior performance, pois em relação ao índice de bem-estar ambiental, a pior situação é do município de Santa Isabel do Pará.

Para a construção de ambos os índices, BS e DS, os indicadores foram agregados segundo dimensões, gerando um índice sintético para cada uma. Dessa forma, para a dimensão ambiental os dois sistemas apresentaram o mesmo resultado tanto para o melhor desempenho, que foi o do município de Belém, quanto para o pior que foi o do município de Santa Isabel do Pará. 
Na dimensão social, ambos os índices também apontam para os mesmos municípios: Belém, como o mais sustentável, e o município de Marituba, como o menos sustentável. Essa é a dimensão em que os resultados dos índices pouco variaram entre os municípios, sendo a maioria classificados como 'intermediário' (no caso do BS) ou 'médio' (no caso do PS). Apesar de Belém encontrar-se em uma posição melhor que os demais municípios, a variação entre eles é sutil. O melhor desempenho nessa dimensão pode ser explicado devido o município concentrar a maior parte dos equipamentos públicos e infraestrutura (IPEA, 2013).

Entretanto, por fazerem parte de uma região metropolitana os municípios circundantes tendem a apresentar, condições sociais semelhantes. É importante evidenciar que esse é o valor médio para a dimensão, o que acaba ocultando as diferenças entre os municípios e amenizando as desigualdades que existem em relação a determinados temas.

Para a dimensão econômica ambos os métodos mostram que Belém apresenta a melhor performance. Já em relação ao pior desempenho, o PS mostra que é Marituba e o BS aponta para Santa Bárbara do Pará, porém com pouca diferença em relação à Santa Isabel do Pará e Marituba, todos classificados como 'potencialmente insustentáveis' para esta dimensão.

Na dimensão institucional, ambos os métodos apontam para Belém a melhor performance. Entretanto, para a pior situação, o BS aponta Castanhal, já para o PS é o município de Benevides. Essa foi uma das dimensões com maior variação entre os municípios, e também em que a maioria apresentou resultados insatisfatórios.

Os resultados de ambos os métodos mostram que apesar da metodologia diferir ao avaliar os indicadores de sustentabilidade, os índices sintéticos finais apresentam uma mesma tendência, com algumas variações. Essas variações podem estar ligadas ao fato de que a análise do PS é uma análise relativa à realidade em que se está avaliando, ou seja, não usa valores de referência para o que é sustentável ou não. Outra razão pode estar ligada ao fato de que a customização das escalas de desempenho dos indicadores no BS é em sua maioria subjetiva, pois apesar de ser baseada em parâmetros, a distribuição dos intervalos é feita de acordo com os conhecimentos de cada autor/pesquisador, o que pode influenciar nos resultados.

Uma desvantagem para o PS seria a necessidade de manusear o software, apesar de ser considerado simples e de fácil manipulação. Já para o BS, seria a necessidade de utilizar valores de referência, parâmetros sobre o que é sustentável ou não; e também a subjetividade na construção das escalas de desempenho do indicador, que pode diferir muito de um autor para outro. Além disso, a necessidade de utilização de parâmetros, para a construção das escalas de desempenho, impossibilita a utilização de alguns indicadores importantes para o desenvolvimento sustentável.

Os dois métodos têm, como produto final, índices sintéticos que são representados graficamente. Esses produtos têm como vantagem a facilidade na comunicação dos resultados e na interpretação, tanto por parte da comunidade científica como, especialmente, por parte de tomadores de decisão, formuladores de políticas públicas e a sociedade em geral. 


\section{CONCLUSÕES}

A aplicação de ambas as métricas de sustentabilidade, Barômetro da Sustentabilidade e Painel da Sustentabilidade, além de fornecer um panorama sobre a sustentabilidade da RMB, também fornece informações importantes a respeito das características de cada ferramenta. A região metropolitana de Belém de forma generalizada apresenta uma situação insatisfatória, porém desigual. O núcleo Belém apresenta uma melhor infraestrutura e serviços urbanos e concentra boa parte dos equipamentos públicos. Em razão disso, se destaca dos demais municípios em todas as dimensões. Já a região periférica apresenta situações precárias em vários aspectos, desde infraestruturais até institucionais.

Em termos gerais, os instrumentos apresentaram resultados semelhantes com algumas distorções, principalmente em relação às dimensões. Essas distorções podem estar relacionadas ao modo em que a interpolação dos valores dos indicadores para as escalas do BS e PS é realizada. A subjetividade na escolha dos indicadores para compor ambos os sistemas, e na construção das escalas de desempenho do BS, são fatores que podem ter relação direta nos resultados. Além disso, há o fato de que o PS não utiliza valores de referência e sim faz uma análise comparativa em relação a determinado contexto, o que diferencia bastante do BS.

Apesar disso, a partir dos resultados encontrados é possível inferir que independentemente da escolha em utilizar uma ferramenta ou outra, ambas oferecem um diagnóstico amplo acerca dos temas e dimensões da sustentabilidade. Essas informações podem servir para basear a formulação de políticas e a definição de ações, além de indicar quais dimensões e em quais municípios essas ações devem ser priorizadas.

\section{REFERÊNCIAS}

ALMEIDA, A. S.; VIEIRA, I. C. G.. Centro de Endemismo Belém: status da vegetação remanescente e desafios para a conservação biológica e restauração ecológica. Revista de

Estudos Universitários, Sorocaba, v.36, p.95-111, 2010.

AMARAL, D. D.; VIEIRA, I. C.G.; SALOMÃO, R. P.; ALMEIDA, S. S.; JARDIM, M. A. G.. The status of conservation of urban forests in eastern Amazonia. Brazilian Journal of Biology, São Carlos, v.72, n.2, 2012. DOI:

http://doi.org/10.1590/S1519-69842012000200005

BRAGA , A.; BÖHM, G. M.; PEREIRA, L. A. A.; SALDIVA, P.. Poluição atmosférica e saúde humana. Revista USP, São Paulo, n.51, p.58-71, 2001.

DOI: http://doi.org/10.11606/issn.2316-9036.v0i51p58-71

BRASIL. Ministério de Educação. Plano Nacional de Educação 2014-2024. Brasília: Ministério de Educação, 2014.

BRITO, F.. O deslocamento da população brasileira para as metrópoles. Estudos Avançados, São Paulo, v.20, n.57, 2006. DOI: http://doi.org/10.1590/S0103-40142006000200017

BRITO, F.; HORTA, C. J. G.; AMARAL, E. F. L.. A urbanização recente no Brasil e as aglomerações urbanas metropolitanas. Belo Horizonte: ABEP, 2001.

BRITO, F.; SOUZA, J.. Expansão urbana nas grandes metrópoles o significado das migrações intrametropolitanas e da mobilidade pendular na reprodução da pobreza. São
Paulo em Perspectiva, v.19, n.4, 2005. DOI: http://dx.doi.org/10.1590/S0102-88392005000400003

CARDOSO, A. S.; TOLEDO, P. M.; VIEIRA, I. C. G.. Barômetro da sustentabilidade aplicado ao município de Moju, estado do Pará. Revista Brasileira de Gestão e Desenvolvimento Regional, Taubaté, v.12, n.1, p.234-263, 2016.

CARDOSO, A. S.; TOLEDO, P. M.; VIEIRA, I. C. G.. Dimensão Institucional da Sustentabilidade e Gestão Ambiental no município de Moju, Pará: uma aplicação do Barômetro da Sustentabilidade. Sustentabilidade em Debate, Brasília, v.5, n.1, p.117-135, 2014. DOI:

http://doi.org/10.18472/SustDeb.v5n2. 2014.10277

DATASUS. Departamento de Informática do Sistema Único de Saúde do Brasil. Informações de saúde. Brasília: DATASUS, 2010.

DENATRAN. Departamento Nacional de Trânsito. Frota de veículos em 2010. Brasília: DENATRAN, 2010.

FERREIRA, L. V.; PAROLIN, P.; MUÑOZ, S. H.; CHAVES, P. P.. O efeito da fragmentação e isolamento florestal das áreas verdes da região metropolitana de Belém. Pesquisas. Botânica, São Leopoldo, n.63, p.357-367, 2012.

FREITAS, R.. Regiões Metropolitanas: uma abordagem conceitual. Humanae, v.1, n.3, p.44-53, 2009. 
GUIMARÃES, R. P.; FEICHAS, S. A. Q.. Desafios na Construção de Indicadores de Sustentabilidade. Ambiente \& Sociedade, Campinas, v.7, n.2, 2009. DOI:

http://doi.org/10.1590/S1414-753X2009000200007

IBGE. Instituto Brasileiro de Geografia e Estatística. Censo 2010a. Rio de Janeiro: IBGE, 2010a.

IBGE. Instituto Brasileiro de Geografia e Estatística. Censo demográfico 2010: Características urbanísticas do entorno dos domicílios. Rio de Janeiro: IBGE, 2010b.

IBGE. Instituto Brasileiro de Geografia e Estatística. Fundações privadas e associações sem fins lucrativos. Rio de Janeiro: IBGE, 2015.

IBGE. Instituto Brasileiro de Geografia e Estatística. Pesquisa de Informações Básicas Municipais: Gestão Pública. Rio de Janeiro: IBGE, 2011.

IISD. International Institute for Sustainable Development. The measure of progress: The Dashboard of Sustainability. Winnipeg: IISD, 2001.

INEP. Instituto Nacional de Estudos e Pesquisas Educacionais Anísio Teixeira. Índice de Desenvolvimento da Educação Básica. Brasília: INEP, 2013.

INEP. Instituto Nacional de Estudos e Pesquisas Educacionais Anísio Teixeira. Indicadores Educacionais. Brasília: INEP, 2010.

INPE. Instituto Nacional de Pesquisas Espaciais. Banco de dados do projeto Programa de Monitoramento da Amazônia por Satélite - PRODES. São José dos Campos: INPE, 2010.

IPEA. Instituto de Pesquisa Econômica Aplicada. Atlas do Desenvolvimento Humano nas Regiões Metropolitanas Brasileiras. Brasília: IPEA, 2014.

IPEA. Instituto de Pesquisa Econômica Aplicada. Desafios contemporâneos na gestão das Regiões

Metropolitanas. Brasília: IPEA, 2011.

IPEA. Instituto de Pesquisa Econômica Aplicada. Desafios da governança metropolitana na região metropolitana de Belém: alguns apontamentos. In: IPEA. Projeto Governança Metropolitana no Brasil: 40 anos de Regiões Metropolitanas no Brasil. Brasília: IPEA, 2013. p.47-67.

KRONEMBERGER, D. M. P.; CARVALHO, C. N.; JUNIOR, J. C.. Indicadores de Sustentabilidade em pequenas bacias hidrográficas: uma aplicação do 'Barômetro da Sustentabilidade' à Bacia de Jurumirim (Angra dos Reis/RJ). Geochimica Brasiliensis, n.18, v.2, p.86-98, 2004. DOI: http://doi.org/10.21715/gb.v18i2.214

KRONEMBERGER, D. M. P.; CLEVELARIO JUNIOR, J.; NASCIMENTO, J. A. S.; COLLARES, J. E. R.; SILVA, L. C. D.. Desenvolvimento sustentável no Brasil: uma análise a partir da aplicação do Barômetro da Sustentabilidade. Sociedade \& Natureza, Uberlândia, n.20, v.1, p.25-50, 2008. DOI: http://doi.org/10.1590/S1982-45132008000100002
LAMEIRA, W. J. M.; VIEIRA, I. C. G.; TOLEDO, P. M.. Panorama da sustentabilidade na fronteira agrícola de bioenergia na Amazônia. Sustentabilidade em Debate, Brasília, v.6, n.2, p.193-210, 2015.

DOI: http://doi.org/10.18472/SustDeb.v6n2.2015.12696

LIMA, J. J. F.; MOYSÉS, A.. Como andam Belém e Goiânia. Rio de Janeiro: Letra Capital: 2009

LIRA, S. W.; CÂNDIDO, G.. A Análise dos modelos de indicadores no contexto do desenvolvimento sustentável. Perspectivas Contemporâneas, Campo Mourão, v.3, n.1, p.31-45, 2008.

MARCHAND, G.; LE TOURNEAU, F. M.. O desafio de medir a sustentabilidade na Amazônia: os principais indicadores e a sua aplicabilidade ao contexto amazônico. In: VIEIRA, I. C. G.; TOLEDO, P. M; SANTOS JÚNIOR, R. A. O.. Ambiente e sociedade na Amazônia: uma abordagem interdisciplinar. Rio de Janeiro: Garamond, 2014. p.155-220.

MORI, K.; CHRISTODOULOU, A.. Review of sustainability indices and indicators: Towards a new City Sustainability Index (CSI). Environmental Impact Assessment Review, v.32, n.1, 2012. DOI: https://doi.org/10.1016/j.eiar.2011.06.001

PEREIRA, F. S.; VIEIRA, I. C. G.. Expansão urbana da Região Metropolitana de Belém sob a ótica de um sistema de índices de sustentabilidade. Revista Ambiente \& Água, Taubaté, v.11, n.3, 2016. DOI: http://doi.org/10.4136/ambiagua. 1878

PRESCOTT-ALLEN, R.. The wellbeing of nations: a countryby-country index of quality of life and the environment. Washington: Island Press, 2001.

SCIPIONI, A.; MAZZI, A.; MASON, M.; MANZARDO, A.. The Dashboard of Sustainability to measure the local urban sustainable development: The case study of Padua Municipality. Ecological Indicators, v.9, p.364-380, 2009. DOI: https://doi.org/10.1016/i.ecolind.2008.05.002

SICHE, R.; AGOSTINHO, F.; ORTEGA, E.; ROMEIRO, A.. Índices versus indicadores: precisões conceituais na discussão da sustentabilidade de países. Ambiente \& Sociedade: Campinas, v.10, n.2, p.137-148, 2007. DOI: http://doi.org/10.1590/S1414-753X2007000200009

SILVA, V. C. S.; VIEIRA, I. C. G.. Barômetro da Sustentabilidade aplicado a assentamentos rurais do leste do Estado do Pará, Brasil. Desenvolvimento e Meio Ambiente, v.36, 2016. DOI: https://doi.org/10.5380/dma.v36i0.39957

SINGH, R. K.; MURTY, H. R.; GUPTA, S. K.; DIKSHIT, A. K.. An overview of sustainability assessment methodologies. Ecological Indicators, v.15, p.281299, 2012. DOI:

https://doi.org/10.1016/j.ecolind.2011.01.007

VAN BELLEN, H. M.. Desenvolvimento Sustentável: uma descrição das principais ferramentas de avaliação. Ambiente \& Sociedade, v.2, n.1, 2004. DOI: http://dx.doi.org/10.1590/S1414-753X2004000100005 